\title{
On the Mechanisms Underlying 3,4-Methylenedioxymethamphetamine Toxicity: The Dilemma of the Chicken and the Egg
}

\author{
E. Puerta I. Hervias N. Aguirre \\ Department of Pharmacology, School of Medicine, University of Navarra, Pamplona, Spain
}

\section{Key Words}

3,4-Methylenedioxymethamphetamine •

5 -Hydroxytryptamine $\cdot$ Serotonin $\cdot$ Dopamine $\cdot$

Hyperthermia $\cdot$ Metabolism $\cdot$ Neurotoxicity

\begin{abstract}
Administration of 3,4-methylenedioxymethamphetamine (MDMA, ecstasy) to various experimental animals has been shown to induce a selective damage to serotonergic axon terminals. While a great consensus appears to exist regarding the causative role of reactive oxygen species (ROS) in the mechanisms underlying MDMA toxicity, the source of free radicals is still a matter of debate. While some authors support dopamine metabolism/oxidation inside 5-hydroxytryptamine (5-HT) terminals as the key factor responsible for ROS formation and final 5-HT terminal degeneration, others believe it is MDMA metabolism into pro-oxidant compounds. Although at first sight both hypotheses appear to contend with each other, it may not be the case. This mini-review was therefore undertaken to try to reconcile both hypotheses and to address the dilemma of the causality of MDMA neurotoxicity.

Copyright $\odot 2009$ S. Karger AG, Basel
\end{abstract}

3,4-Methylenedioxymethamphetamine (MDMA or ecstasy) is an illicit drug used by young adults in the USA, Europe and elsewhere. The appeal of MDMA is related to its unique profile of psychotropic actions, which includes amphetamine-like stimulant effects, coupled with feelings of increased emotional sensitivity and closeness to others $[1,2]$. However, it is worth noting that MDMA-related medical complications have risen more than 20 -fold in recent years, consistent with the increasing popularity of the drug [3]. The serious adverse effects of MDMA intoxication include cardiac arrhythmias, hypertension, hyperthermia, serotonin (5-HT) syndrome, hyponatremia, liver complications, seizures, coma and, in rare cases, death [4]. Further, accumulating evidence also indicates that long-term MDMA abuse is associated with cognitive impairments and mood disturbances, which can last for months after the cessation of drug intake [5-7].

On the other hand, it is well known that single or repeated injections of MDMA can cause long-lasting changes in neurochemical and histological markers of serotonergic function in brains of rats [8-11], primates [12, 13] and, possibly, humans [14]. Such neurotoxicity is evidenced by the decline in the activity of tryptophan hydroxylase [15], a decrease in the content of 5-hydroxytryptamine (5-HT) [16], a lower density of $\left[{ }^{3} \mathrm{H}\right]$ paroxetinelabeled 5-HT transporters in several regions of the brain $[17,18]$ and impairments of central 5-HT function. This constellation of findings, coupled with neuroanatomic observations using different techniques such as silver impregnation methods [19], neuronal staining for neuronal death [20] and immunohistochemistry [21], strongly sug-

Norberto Aguirre

Department of Pharmacology, School of Medicine, University of Navarra

Irunlarrea 1

ES-31008 Pamplona (Spain)

Tel. +34948425 600, Fax +34948425 649, E-Mail popi@ unav.es 
Table 1. Drugs known to prevent MDMA-induced 5-HT depletion by preventing the acute hyperthermic response after MDMA administration

\begin{tabular}{lll}
\hline Pharmacologic mechanism & Drug & Reference \\
\hline Glutamate receptor antagonists & MK-801, CGS 19755, NBQX & Farfel and Seiden [122] \\
Free radical scavenger & N-tert-butyl- $\alpha$-phenylnitrone & Che et al. [123] but see [48] \\
5-HT 2 receptor antagonist & Ketanserin & Malberg et al. [124] \\
Dopamine synthesis inhibitor & $\alpha$-Methyl-p-tyrosine & Malberg et al. [124] \\
Nitric oxide synthase inhibitors & N(G)-nitro-L-arginine methyl ester & Taraska and Finnegan [125] \\
GABA mimetics & Chlomethiazole & Colado et al. [126] \\
Anesthetic & Pentobarbitone & Colado et al. [127] \\
Inhibitor of glucose transport/phosphorylation & 2-Deoxy-D-glucose & Hervias et al. [18] \\
Glutathione conjugation & Diethylmaleate & O’Shea et al. [128] \\
Cannabinoid receptor agonists & $\Delta$ 9-Tetrahydrocannabinol; CP 55940 & Morley et al. [129] \\
\hline
\end{tabular}

gests that MDMA damages 5-HT terminals in rats [reviewed by 22].

According to these evidences, a number of investigators have also tested whether MDMA abuse results neurotoxic in the human brain [23-33]. Some of these studies concluded that MDMA may also be toxic to humans, since the 5-hydroxyindoleacetic acid levels in the CSF are reduced in MDMA abusers [23, 24, 26, 28, 29]. Recent advances in neuroimaging techniques have been applied to the study of the serotonin system in the brains of humans with a history of MDMA abuse. Positron emission tomography or single-photon emission computed tomography used in combination with a 5-HT transporter ligand found a lower density of brain 5-HT transporter sites (SERT) and a reduction in their function in MDMA users [14, 27, 34-36].

While the exact mechanisms underlying MDMA-induced neurotoxicity remain unclear, the close relationship between hyperthermia and neurotoxicity engendered by MDMA is well established [37-41]. Thus, a common feature of many drugs known to prevent MDMA toxicity relies on their ability to block the acute hyperthermia induced by MDMA, with such protection disappearing if the temperature of the rats is kept elevated (table 1). Similarly, other nonpharmacological manipulations capable of preventing the acute hyperthermic response caused by MDMA also provide substantial protection against the neurotoxic effects of the drug [42]. Furthermore, the converse also occurs; any manipulation known to potentiate MDMA-induced hyperthermia exacerbates long-term 5-HT deficits caused by the drug and small increases in ambient temperature lead to large changes in both core body temperature and MDMA-in- duced 5-HT neurotoxicity in the rat [39-41]. This represents a clinically relevant aspect in MDMA abusers, since MDMA is often taken at 'rave parties,' where dancing takes place in crowded conditions with a high ambient temperature, physical activity and dehydration, which may all contribute to increase the hyperthermic response induced by MDMA and thereby promote acute or longterm complications [7]. However, some compounds have been shown to protect MDMA-induced serotonergic deficits without affecting hyperthermia [43-45], suggesting that hyperthermia is not a primary contributing factor to 5-HT neurotoxicity [46], despite its key modulator effects [47].

On the other hand, there is overwhelming evidence supporting the role of oxidative stress due to the formation of free radicals in MDMA-induced damage to 5-HT terminals. The findings that free radical scavengers and antioxidants attenuate the MDMA-induced 5-HT deficits $[15,48-50]$ provide indirect evidence for the involvement of free radicals in the mechanism of MDMA neurotoxicity. In addition, MDMA has been reported to produce cellular changes, e.g. lipid peroxidation or protein nitration, consistent with the formation of free radicals [51-53]. Finally, Colado et al. [52, 54, 55], as well as Shankaran et al. [56-58], have demonstrated that MDMA increases the formation of hydroxyl radicals, as evidenced by an increased extracellular concentration of 2,3-dihydroxybenzoic acid following salicylic acid administration.

Despite the general agreement on oxidative stress as one of the main causes underlying MDMA-induced 5HT toxicity, the source of reactive oxygen species (ROS) is still a matter of debate. Several authors have suggested 
that the depletion of 5-HT in the rat brain is dependent, in part, upon dopamine (DA) metabolism/oxidation inside 5-HT terminals [59-61]. Other authors, however, have proposed that some quinone thioether adducts resulting from the peripheral metabolism of MDMA might be the ultimate mediators of its neurotoxicity $[39,62-$ 66].

\section{Involvement of DA in the Mechanisms Underlying MDMA Toxicity}

A decade ago, Sprague et al. wrote the review entitled 'An integrated hypothesis for the serotonergic axonal loss induced by 3,4-methylenedioxymethamphetamine' [61]. In this work the authors integrated the current knowledge, at that time, proposing the following hypothesis as a plausible sequence of events leading to long-term 5-HT deficits after MDMA. (A) MDMA induces an acute release of 5-HT and of DA. (B) 5-HT released by MDMA activates postsynaptic $5-\mathrm{HT}_{2 \mathrm{~A} / 2 \mathrm{C}}$ receptors located on GABA interneurons resulting in a decrease in GABAergic transmission and an increase in DA release and synthesis. (C) Extracellular DA, present in abnormally high amounts, then enters the depleted 5-HT terminal by means of the SERT, and (D) once inside the 5-HT terminal, $\mathrm{DA}$ is metabolized by monoamine oxidase- $\mathrm{B}$ (MAO$\mathrm{B})$ resulting in ROS formation and selective degeneration of the serotonergic terminals. A thorough revision of all the evidences supporting this hypothesis can be found in the above-mentioned review, and so, we will briefly summarize the main findings.

MDMA administration to rats induces an acute and rapid release of 5-HT. This has been broadly demonstrated not only in vitro following addition of MDMA to brain slices or synaptosomal preparations but also using in vivo microdialysis or voltametry [reviewed by 22]. MDMAinduced 5-HT release is also reflected by the fact that the 5-HT concentration in brain tissue decreases markedly during the first few hours following drug administration $[16,67-72]$. On the other hand, it is also well known that MDMA causes both transporter- and impulse-mediated DA release, an effect that is in part dependent upon 5-HT transmission [73-74]. MDMA-induced DA release is potentiated in 5-hydroxytryptophan-treated rats [75], which is consistent with the view that 5-HT release after MDMA contributes to the effect of MDMA on DA release [74]. Microdialysis studies have shown that blockade $5-\mathrm{HT}_{2}$ receptors significantly reduces the efflux of endogenous DA [76-78], whereas the activation of these receptors ap- pears to be necessary for MDMA-induced DA release [79-81], free radical formation [56, 57, 75] and neurotoxicity $[82,83]$. Consistent with these observations, $5-\mathrm{HT}_{2 \mathrm{~A}}$ antagonists attenuated the increased L-DOPA utilization and extracellular levels of DA seen after MDMA administration as well as MDMA-induced neurotoxicity [78, 84]. Further, Nash and Nichols [85], using in vivo microdialysis, showed that the acute increase in extracellular DA concentration following MDMA was negatively correlated with the concentrations of 5-HT and its major metabolite, 5-hydroxyindoleacetic acid measured 7 days following drug administration. In a similar fashion, Shankaran et al. [56] showed that mazindol, a DA uptake inhibitor, suppressed acute DA release and 2,3-dihydroxybenzoic acid formation and attenuated the longterm depletion of 5-HT caused by MDMA administration in rats. It is worth mentioning that 5-HT precursors, tryptophan or 5-hydroxytryptophan, attenuate rather that exacerbate MDMA-induced 5-HT depletions in rats [86]. Although apparently at odds with the above evidences supporting the role of the 5-HT-DA connection in the mechanisms underlying MDMA toxicity, it appears reasonable to think that these amino acids may compete with tyrosine for the large neutral amino acid transporter located at the blood-brain barrier to enter the brain [87] (see below and also fig. 1).

The GABAergic system is thought to serve as a modulator of dopaminergic activity. Colado et al. [88] demonstrated that chlomethiazole, a GABA agonist, attenuated the serotonergic toxicity induced by MDMA treatment in rats, although in part due to the temperature-lowering effect of chlomethiazole. In another investigation, Yamamoto et al. [77] conducted microdialysis studies and observed an MDMA-induced increase in extracellular DA coupled with a decrease in extracellular GABA levels in the rat striatum that was reversed by the $5-\mathrm{HT}_{2 \mathrm{~A}}$ receptor antagonist, ritanserin. It is possible that MDMA-mediated reduction in GABA might enhance its effects on DA synthesis and release $[61,89,90]$, thus potentiating its neurotoxic effects in the long term.

It is known that DA can enter the 5-HT terminal by means of the 5-HT transporter, an effect that may be especially relevant when DA is present in abnormally high amounts [91-94]. DA uptake by SERT is effectively inhibited by 5-HT uptake blockers [91], providing a likely explanation of how selective serotonin reuptake inhibitors prevent both the acute increase in hydroxyl radical formation which follows MDMA [57] and the long-lasting neurotoxic effects $[10,40,95,96]$. Moreover, inhibition of DA metabolism is protective, as evidenced by the block-

Mechanisms of MDMA-Induced 5-HT 


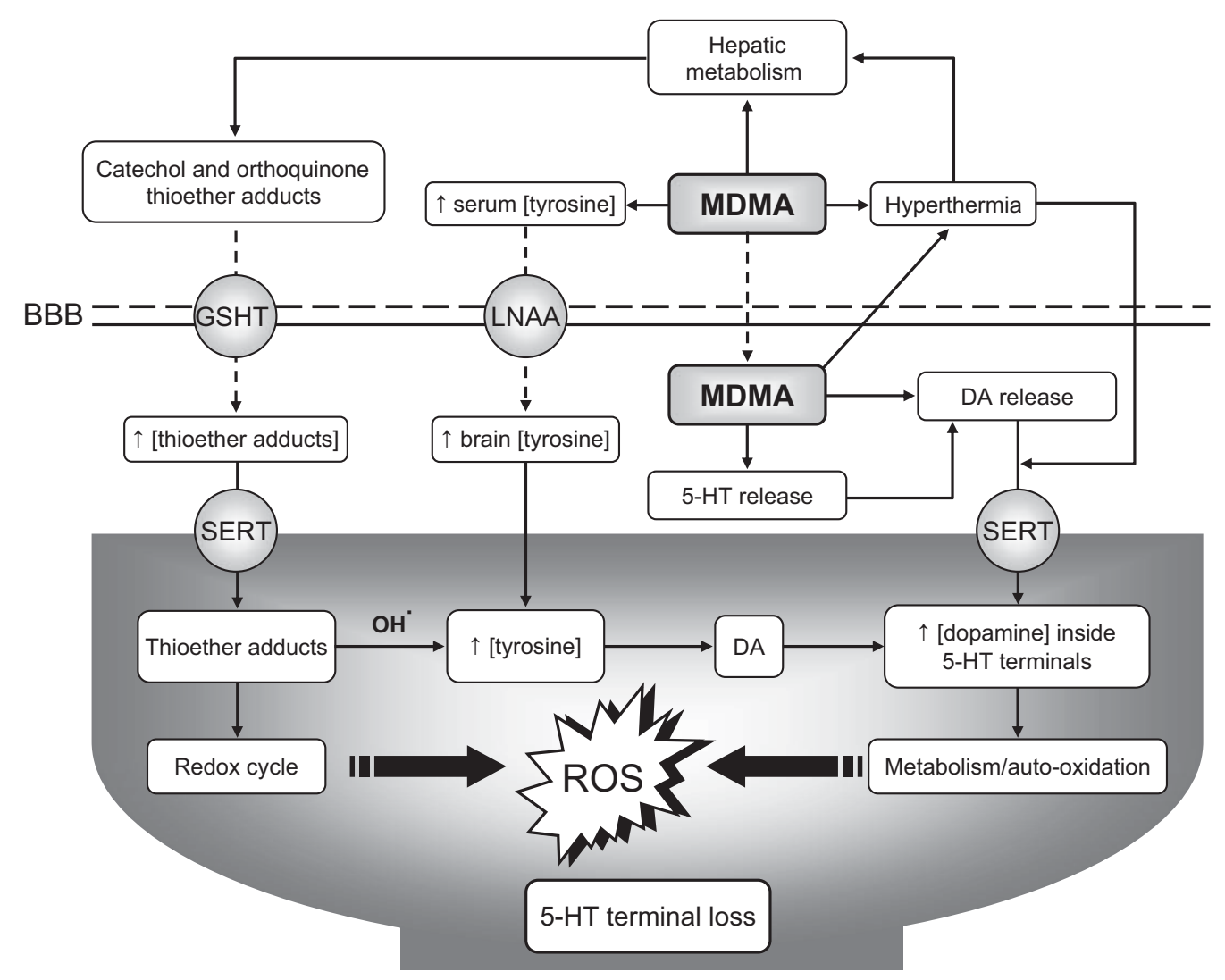

Fig. 1. The proposed sequence of events resulting in serotonergic neurotoxicity after MDMA. Formation of toxic MDMA metabolites and DA metabolism promotes an oxidative environment responsible for MDMA toxicity towards 5 -HT terminals in the brain. $\mathrm{BBB}=$ Blood-brain barrier; GSHT = glutathione transporter; LNAA = large neutral amino acid transporter.

ade of MDMA toxicity. Sprague and Nichols [51] showed that MAO-B metabolizes DA inside the 5-HT terminal, producing hydrogen peroxide which could lead to lipid peroxidation and general oxidative stress. Consistent with these findings, MAO-B inhibitors such as L-deprenyl or MDL-72974 or knocking down MAO-B enzyme expression using antisense oligonucleotides attenuate the long-term MDMA-induced 5-HT loss [51, 97].

Treatment with $\alpha$-methyl-p-tyrosine, a DA synthesis inhibitor, prior to the administration of MDMA protects against 5-HT deficits [98]. In a similar fashion, complete protection against MDMA neurotoxicity is afforded when DA terminals are destroyed by prior administration of 6-hydroxydopamine [99]. Conversely, an increase in MDMA-induced neurotoxicity is observed following pretreatment with the DA precursor L-DOPA [100]. More recently, Simantov and Tauber [101] demonstrated that programmed cell death caused by MDMA could be potentiated by DA but not by $5-\mathrm{HT}$ in a human serotonergic cell line.

Despite all above evidences on the role of DA in mediating MDMA toxicity, there are also caveats associated with how DA may mediate MDMA-induced 5-HT depletions in brain areas that are sparsely innervated by DA such as the frontal cortex or the hippocampus. Another important drawback of the 'dopamine hypothesis' relies on the fact that MDMA administered directly into the brain causes DA release but not long-term 5-HT depletions [102]. Further, Ricaurte's group demonstrated that rats depleted of vesicular and cytoplasmic DA, using reserpine in combination with $\alpha$-methyl-p-tyrosine, were still susceptible to MDMA neurotoxicity when drug-in- 
duced hypothermia was averted by raising ambient temperature, suggesting that endogenous DA is not essential for the expression of MDMA-induced toxicity [38].

These important issues have been expanded upon recently [59]. The novel findings from this study are twofold. First, these authors showed that MDMA increases the concentrations of tyrosine in DA-sparse brain regions, which is converted to DOPA via the nonenzymatic hydroxylation of tyrosine to DOPA and subsequently to DA via aromatic L-amino acid decarboxylase. Further, conversion of tyrosine into DA can directly mediate toxicity as blockade of L-amino acid decarboxylase attenuates MDMA-induced 5-HT depletions. These findings do not contradict Ricaurte's data (see above) as endogenous DA may not be essential for MDMA toxicity, but DA formed within 5-HT terminals from tyrosine may be a critical factor. Second, the tyrosine levels increased in the brain after systemic but not after centrally administered MDMA, which could explain why MDMA is not toxic when directly administered into the brain $[40,65$, 102].

It has been consistently shown that the striatum is more resistant to MDMA-induced 5-HT loss than the hippocampus and cortex $[39,42,43,103,104]$. Similar findings were described by Breier et al. [59] despite reporting a higher tyrosine concentration rise after MDMA in the striatum as compared to the hippocampus. A plausible explanation given by the authors for this apparent discrepancy may be related to the differential presence of DA endogenous to each region. Thus, DA terminals of the striatum may buffer much of the increased tyrosine after MDMA, whereas absence of DA terminals in the hippocampus may render this brain region more vulnerable to lower tyrosine concentrations due to its lower capacity to enzymatically metabolize tyrosine to DA for neurotransmission and subsequent enzymatic degradation [59].

Noteworthily, Breier et al. [59] assume that the preexistence of hydroxyl free radicals is responsible for the oxidation of tyrosine into DOPA. This issue is of key importance, especially if we take into account that a systemic injection of L-tyrosine in combination with the intrastriatal perfusion of MDMA in hyperthermic rats does not result in long-lasting reductions in 5-HT [66]. It should be noted that the dose of L-tyrosine and the concentration of MDMA in the perfusate used in this latter study give rise to the range of extracellular MDMA and serum concentrations of L-tyrosine observed following peripheral administration of neurotoxic doses of MDMA [65, 66].

Mechanisms of MDMA-Induced 5-HT Toxicity

\section{Involvement of MDMA Metabolism in the Mechanisms Underlying MDMA Toxicity}

Since direct injection of MDMA into the brain fails to reproduce the serotonergic neurotoxicity seen following systemic administration $[40,65,102]$, some authors have postulated that peripheral metabolism of MDMA into toxic compounds is responsible for neurotoxicity. In rats, MDMA is mainly $\mathrm{N}$-demethylated by several cy tochrome $\mathrm{P} 450$ isoenzymes to form 3,4-methylenedioxyamphetamine (MDA). MDMA and MDA are further O-demethylated to 3,4-dihydroxymethamphetamine and 3,4-dihydroxyamphetamine, respectively (fig. 2). 3,4-Dihydroxymethamphetamine and dihydroxyamphetamine are highly redox-unstable catechols and can be rapidly oxidized to their corresponding orthoquinones forming adducts with GSH and other thiol-containing compounds [105-108].

Due to their structure, these catechols would not be expected to cross the blood-brain barrier. However, the rapidly formed quinones may conjugate with GSH to form adducts such as 5-(glutathion-S-yl)- $\alpha$-methyldopamine (5-GSyl- $\alpha-\mathrm{MeDA}$ ) or 5-(glutathion-S-yl)-N-methyl- $\alpha$-MeDA $[108,109]$ that may cross the blood-brain barrier using a GSH transporter. Indeed, the brain uptake index for 5-GSyl- $\alpha$-MeDA is reduced by GSH coadministration, indicating a competitive uptake mechanism [110]. Further support for the possible role of these compounds arose from the observation that treatment with acivicin, a $\gamma$-glutamyl transpeptidase inhibitor (an enzyme involved in the breakdown of GSH and GSH Sconjugates), not only increased the brain uptake index of 5-GSyl- $\alpha$-MeDA but also the neurotoxicity of systemically administered MDA or MDMA, presumably due to increased concentrations of thioether conjugates in the brain [64]. Interestingly, intracerebroventricular administrations of GSH or $\mathrm{N}$-acetylcysteine conjugates of MDMA metabolites resemble not only some of the acute neurobehavioral effects of the parent drug but also its neurotoxic pattern $[62-64,110,111]$.

The in vivo detection of quinone thioether adducts in the brain of rats after systemic administration of MDMA and the evaluation of the neurotoxicity of some of these metabolic species further strengthens the hypothesis that MDMA metabolic disposition contributes significantly to the induction of neurotoxicity [112]. Moreover, the capability of some of these putative thioether adducts of MDMA metabolites to generate ROS in a 5-HT-transporter-dependent manner has been demonstrated [93]. Cytotoxicity of these metabolites has been shown not

Neuropsychobiology 2009;60:119-129 


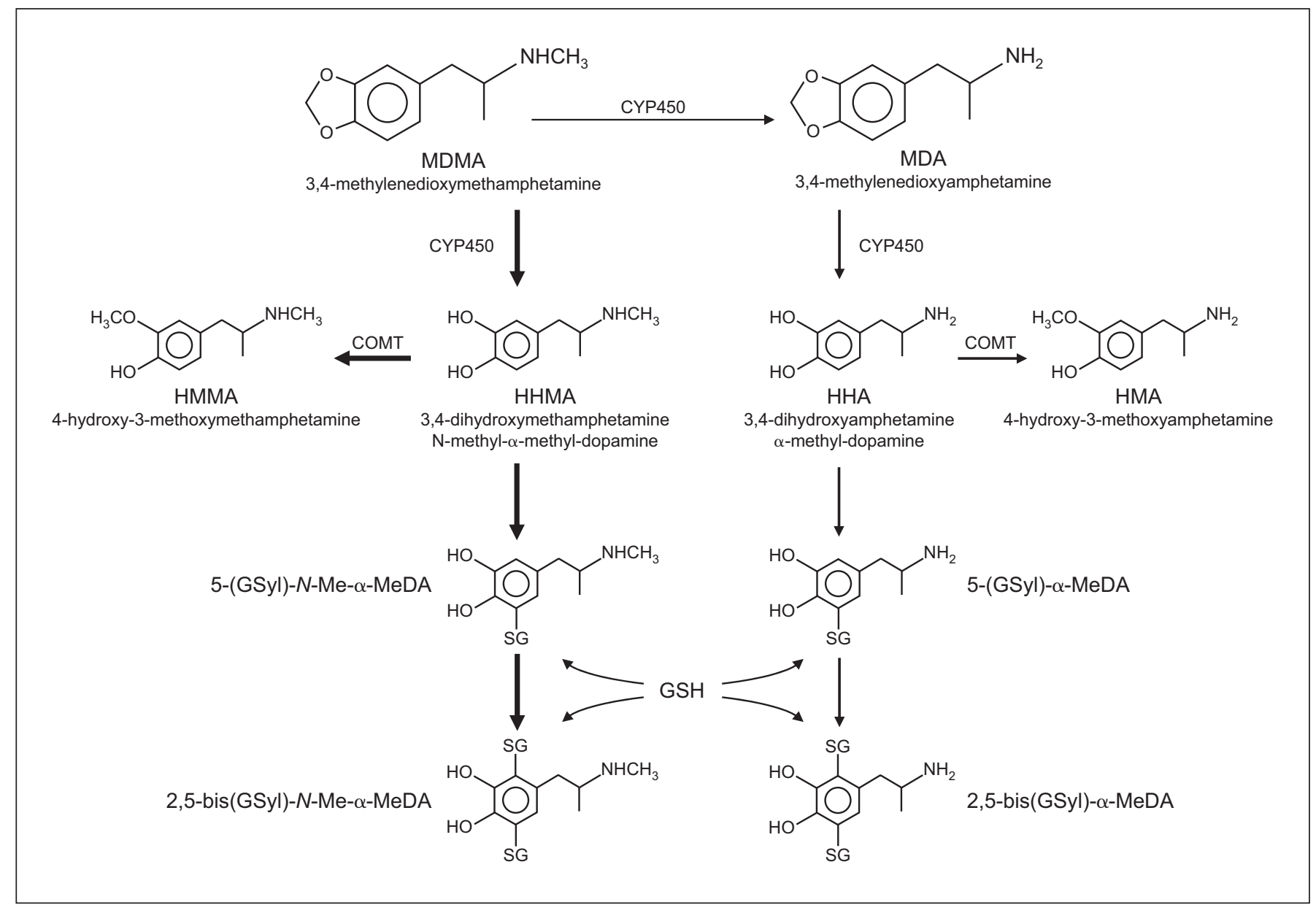

Fig. 2. Postulated pathways of MDMA metabolism [adapted from 88, 98]. Only structures considered in this mini-review are shown.

only in neurons [113] but also in other tissues such as cadiomyocytes [114], hepatocytes $[115,116]$ or human renal proximal tubular cells [117]. Importantly, these cytotoxic effects are aggravated under hyperthermic conditions $[118,119]$ and can be formed by human liver microsomes in a CYP2D6-dependent manner [111, 120].

As stated above, a close relationship appears to exist between MDMA-induced changes in core body temperature and long-term 5-HT loss. Accordingly, Goñi-Allo et al. [39] investigated whether MDMA metabolic disposition is affected by changes in core body temperature. These authors showed that there is a direct relationship between plasma concentrations of MDMA metabolites and core body temperature. The administration of MDMA at $15^{\circ} \mathrm{C}$ blocked the hyperthermic response and long-term 5-HT depletion found in rats treated at an am- bient temperature of $22^{\circ} \mathrm{C}$. At $15^{\circ} \mathrm{C}$, the plasma concentrations of MDMA were significantly increased, whereas those of MDA, 4-hydroxy-3-methoxymethamphetamine or 4-hydroxy-3-methoxyamphetamine (fig. 2) were reduced when compared to rats treated at $22^{\circ} \mathrm{C}$. By contrast, hyperthermia and 5-HT deficits were exacerbated in rats treated at $30^{\circ} \mathrm{C}$. Noteworthily, the plasma concentrations of MDMA metabolites were greatly enhanced in these animals. Furthermore, interfering in MDMA metabolism using the catechol-O-methyltransferase inhibitor entacapone potentiated the neurotoxicity of MDMA, indicating that metabolites that are substrates for this enzyme may contribute to neurotoxicity. This study became the first report showing a direct relationship between core body temperature and MDMA metabolism - a finding that has implications on both the temperature depen- 
dence of the mechanism of MDMA neurotoxicity and human use, as hyperthermia is often associated with MDMA abuse in humans.

In agreement with other authors, the effects produced by MDMA are likely to be a result of its metabolism to not 1 neurotoxic thioether metabolite but a combination of several adducts already mentioned or adducts still to be discovered [121], and in light of the above-mentioned findings, we believe this metabolic pathway to be an area of particular relevance to human users of MDMA. It is important to note that enzymes that participate in the activation of MDMA (CYP2D6) and inactivation of MDMA metabolites (COMT) are highly polymorphic in the human, and so, the fraction converted to toxic metabolites may vary greatly in human abusers exposed to similar doses of MDMA [112].

According to the above-mentioned findings there appears to exist overwhelming data supporting each of the 2 hypotheses, making it difficult to opt for one of them. However, it may not be the case. The tyrosine/DA hypothesis states that the pre-existence of hydroxyl radical is necessary for the conversion of tyrosine into DOPA. In an elegant study by Jones et al. [93] it was shown that 5-(GSyl)- $\alpha$-MeDA and 2,5-bis(GSyl)- $\alpha$-MeDA, and to a lesser extent MDA and MDMA, induced a concentration- and time-dependent increase in ROS formation in human SERT-transfected cells. Moreover, both metabo- lites stimulated DA uptake in these cells, an effect that contributed further to ROS formation and that was attenuated by fluoxetine. Moreover, rats treated with a nontoxic dose of MDMA showed significant reductions in brain 5-HT content when given under heating conditions or if combined with entacapone or acivicin, which interfere with MDMA metabolism or increase brain MDMA metabolite availability, respectively. By contrast, the brain 5-HT content remained unchanged after the administration of a nontoxic dose of MDMA in combination with a dose of L-tyrosine known to produce a similar increase in serum tyrosine levels to those found after a toxic dose of MDMA [66]. Altogether, these data indicate that while tyrosine may contribute to MDMA-induced toxicity, MDMA metabolism appears to be the key limiting step, which somehow unravels the dilemma of the chicken and the egg. As depicted in figure 1, we propose that both tyrosine and MDMA metabolism into pro-oxidant compounds act in concert inside the serotonergic terminals to promote oxidative stress and final terminal loss.

\section{Acknowledgments}

The authors would like to thank the Ministerio de Educación y Ciencia for a fellowship to E. P. This work was supported by grants from the Ministerio de Educación y Ciencia (SAF200507919-C02-02) and Ministerio de Sanidad y Consumo (PNSD).

\section{References}

1 Liechti ME, Vollenweider FX: Which neuroreceptors mediate the subjective effects of MDMA in humans? A summary of mechanistic studies. Hum Psychopharmacol 2001; 16:589-598.

-2 Vollenweider FX, Gamma A, Liechti M, Huber T: Psychological and cardiovascular effects and short-term sequelae of MDMA ('ecstasy') in MDMA-naive healthy volunteers. Neuropsychopharmacology 1998;19: 241-251.

$\checkmark 3$ Baumann MH, Wang X, Rothman RB: 3,4-Methylenedioxy metha mphetamine (MDMA) neurotoxicity in rats: a reappraisal of past and present findings. Psychopharmacology (Berl) 2007;189:407-424.

4 Schifano F: A bitter pill: overview of ecstasy (MDMA, MDA)-related fatalities. Psychopharmacology (Berl) 2004;173:242-248.

5 Morgan MJ: Ecstasy (MDMA): a review of its possible persistent psychological effects. Psychopharmacology (Berl) 2000;152:230248
6 Parrott AC: Recreational ecstasy/MDMA, the serotonin syndrome, and serotonergic neurotoxicity. Pharmacol Biochem Behav 2002;71:837-844.

7 Parrott AC: MDMA in humans: factors which affect the neuropsychobiological profiles of recreational ecstasy users, the integrative role of bioenergetic stress. J Psychopharmacol 2006;20:147-163.

8 Schmidt CJ, Wu L, Lovenberg W: Methylenedioxymethamphetamine: a potentially neurotoxic amphetamine analogue. Eur J Pharmacol 1986;124:175-178.

$\checkmark 9$ Schmidt CJ: Neurotoxicity of the psychedelic amphetamine, methylenedioxymethamphetamine. J Pharmacol Exp Ther 1987;240: $1-7$.

10 Aguirre N, Ballaz S, Lasheras B, Del Río J: MDMA ('Ecstasy') enhances 5-HT1A receptor density and 8-OH-DPAT-induced hypothermia: blockade by drugs preventing 5-hydroxytryptamine depletion. Eur J Pharmacol 1998;346:181-188.
11 Barrionuevo M, Aguirre N, Del Río J, Lasheras B: Serotonergic deficits and impaired passive-avoidance learning in rats by MDEA: a comparison with MDMA. Pharmacol Biochem Behav 2000;65:233-240.

12 Hatzidimitriou G, McCann UD, Ricaurte G.A: Altered serotonin innervation patterns in the forebrain of monkeys treated with (+/-)3,4-methylenedioxymethamphetamine seven years previously: factors influencing abnormal recovery. J Neurosci 1999;19: 5096-5107.

$\checkmark 13$ Hatzidimitriou G, Tsai EH, McCann UD, Ricaurte GA: Altered prolactin response to M-chlorophenylpiperazine in monkeys previously treated with 3,4-methylenedioxymethamphetamine (MDMA) or fenfluramine. Synapse 2002;44:51-57.

14 McCann UD, Szabo Z, Seckin E, Rosenblatt P, Mathews WB, Ravert HT, Dannals RF, Ricaurte GA: Quantitative PET studies of the serotonin transporter in MDMA users and controls using [11C]McN5652 and [11C] DASB. Neuropsychopharmacology 2005;30: 1741-1750. 
15 Stone DM, Johnson M, Hanson GR, Gibb JW: Acute inactivation of tryptophan hydroxylase by amphetamine analogs involves the oxidation of sulfhydryl sites. Eur J Pharmacol 1989;172:93-97.

-16 Aguirre N, Galbete JL, Lasheras B, Del Río J: Methylenedioxymethamphetamine induces opposite changes in central pre- and postsynaptic 5-HT1A receptors in rats. Eur J Pharmacol 1995;281:101-105.

-17 Battaglia G, Yeh SY, O’Hearn E, Molliver ME, Kuhar MJ, De Souza EB: 3,4-Methylenedioxymethamphetamineand3,4-methylenedioxyamphetamine destroy serotonin terminals in rat brain: quantification of neurodegeneration by measurement of $[3 \mathrm{H}]$ paroxetine-labeled serotonin uptake sites. J Pharmacol Exp Ther 1987;242:911916.

18 Hervias I, Lasheras B, Aguirre N: 2-DeoxyD-glucose prevents and nicotinamide potentiates 3,4-methylenedioxymethamphetamine-induced serotonin neurotoxicity. J Neurochem 2000;75:982-990.

19 Commins DL, Vosmer G, Virus RM, Woolverton WL, Schuster CR, Seiden LS: Biochemical and histological evidence that methylenedioxymethylamphetamine (MDMA) is toxic to neurons in the rat brain. J Pharmacol Exp Ther 1987;241:338-345.

20 Schmued LC: Demonstration and localization of neuronal degeneration in the rat forebrain following a single exposure to MDMA. Brain Res 2003;974:127-133.

-21 O’Hearn E, Battaglia G, De Souza EB, Kuhar MJ, Molliver ME: Methylenedioxyamphetamine (MDA) and methylenedioxymethamphetamine (MDMA) cause selective ablation of serotonergic axon terminals in forebrain: immunocytochemical evidence for neurotoxicity. J Neurosci 1988;8:2788-2803.

-22 Green AR, Mechan AO, Elliott JM, O'Shea E, Colado MI: The pharmacology and clinical pharmacology of 3,4-methylenedioxymethamphetamine (MDMA, 'ecstasy'). Pharmacol Rev 2003;55:463-508.

23 Ricaurte GA, DeLanney LE, Wiener SG, Irwin I, Langston JW: 5-Hydroxyindoleacetic acid in cerebrospinal fluid reflects serotonergic damage induced by 3,4-methylenedioxymethamphetamine in CNS of non-human primates. Brain Res 1988;474:359-363.

24 Ricaurte GA, Finnegan KT, Irwin I, Langston JW: Aminergic metabolites in cerebrospinal fluid of humans previously exposed to MDMA: preliminary observations. Ann NY Acad Sci 1990;600:699-710.

- 25 Price LH, Ricaurte GA, Krystal JH, Heninger GR: Neuroendocrine and mood responses to intravenous L-tryptophan in 3,4-methylenedioxymethamphetamine (MDMA) users: preliminary observations. Arch Gen Psychiatry 1989;46:20-22.
26 McCann UD, Ridenour A, Shaham Y, Ricaurte GA: Serotonin neurotoxicity after (+/-)3,4-methylenedioxymethamphetamine (MDMA; 'ecstasy'): a controlled study in humans. Neuropsychopharmacology 1994;10: 129-138.

27 McCann UD, Szabo Z, Scheffel U, Dannals RF, Ricaurte GA: Positron emission tomographic evidence of toxic effect of MDMA ('ecstasy') on brain serotonin neurons in human beings. Lancet 1998;352:1433-1437.

28 McCann UD, Mertl M, Eligulashvili V, Ricaurte GA: Cognitive performance in (+/-) 3,4-methylenedioxymethamphetamine (MDMA, 'ecstasy') users: a controlled study. Psychopharmacology (Berl) 1999;143:417425.

29 Bolla KI, McCann UD, Ricaurte GA: Memory impairment in abstinent MDMA ('Ecstasy') users. Neurology 1998;51:1532-1537.

30 Semple DM, Ebmeier KP, Glabus MF, O'Carroll RE, Johnstone EC: Reduced in vivo binding to the serotonin transporter in the cerebral cortex of MDMA ('ecstasy') users. Br J Psychiatry 1999;175:63-69.

-31 Gerra G, Zaimovic A, Ferri M, Zambelli U, Timpano M, Neri E, Marzocchi GF, Delsignore R, Brambilla F: Long-lasting effects of (+/-)3,4-methylenedioxymethamphetamine (ecstasy) on serotonin system function in humans. Biol Psychiatry 2000;47: 127-136.

-32 Kish SJ, Furukawa Y, Ang L, Vorce SP, Kalasinsky KS: Striatal serotonin is depleted in brain of a human MDMA (ecstasy) user. Neurology 2000;55:294-296.

33 Buchert R, Obrocki J, Thomasius R, Vaterlein $\mathrm{O}$, Petersen K, Jenicke L, Bohuslavizki $\mathrm{KH}$, Clausen M: Long-term effects of 'ecstasy' abuse on the human brain studied by FDG PET. Nucl Med Commun 2001;22:889897.

34 Ricaurte GA, McCann UD, Szabo Z, Scheffel $\mathrm{U}$ : Toxicodynamics and long-term toxicity of the recreational drug, 3,4-methylenedioxymethamphetamine (MDMA, 'Ecstasy') Toxicol Lett 2000;112-113:143-146.

35 Buchert R, Thomasius R, Nebeling B, Petersen K, Obrocki J, Jenicke L, Wilke F, Wartberg L, Zapletalova P, Clausen M: Long-term effects of 'ecstasy' use on serotonin transporters of the brain investigated by PET. J Nucl Med 2003;44:375-384.

- 36 Buchert R, Thomasius R, Wilke F, Petersen K, Nebeling B, Obrocki J, Schulze O, Schmidt $\mathrm{U}$, Clausen M: A voxel-based PET investigation of the long-term effects of 'Ecstasy' consumption on brain serotonin transporters. Am J Psychiatry 2004;161:1181-1189.

37 Broening HW, Bowyer JF, Slikker W Jr: Agedependent sensitivity of rats to the long-term effects of the serotonergic neurotoxicant (+/-)3,4-methylenedioxymethamphetamine (MDMA) correlates with the magnitude of the MDMA-induced thermal response. J Pharmacol Exp Ther 1995;275:325-333.
38 Yuan J, Cord BJ, McCann UD, Callahan BT, Ricaurte GA: Effect of depleting vesicular and cytoplasmic dopamine on methylenedioxymethamphetamine Neurotoxicity. J Neurochem 2002;80:960-969.

-39 Goñi-Allo B, O Mathúna B, Segura M, Puerta E, Lasheras B, de la Torre R, Aguirre N: The relationship between core body temperature and 3,4- methylenedioxymethamphetamine metabolism in rats: implications for neurotoxicity. Psychopharmacology (Berl) 2008;197:263-278.

40 Goñi-Allo B, Puerta E, Hervias I, Di Palma R, Ramos M, Lasheras B, Aguirre N: Studies on the mechanisms underlying amiloride enhancement of 3,4-methylenedioxymethamphetamine-induced serotonin depletion in rats. Eur J Pharmacol 2007;562:198-207.

41 Malberg JE, Seiden LS: Small changes in ambient temperature cause large changes in 3,4-methylenedioxymethamphetamine (MDMA)-induced serotonin neurotoxicity and core body temperature in the rat. J Neurosci 1998; 18:5086-5094.

42 Sprague JE, Banks ML, Cook VJ, Mills EM: Hypothalamic-pituitary-thyroid axis and sympathetic nervous system involvement in hyperthermia induced by 3,4-methylenedioxymethamphetamine (Ecstasy). J Pharmacol Exp Ther 2003;305:159-166.

-43 Sanchez V, O'Shea E, Saadat KS, Elliott JM, Colado MI, Green AR: Effect of repeated ('binge') dosing of MDMA to rats housed at normal and high temperature on neurotoxic damage to cerebral 5-HT and dopamine neurones. J Psychopharmacol 2004;18:412416.

44 Zheng Y, Laverty R: Role of brain nitric oxide in (+/-)3,4-methylenedioxymethamphetamine (MDMA)-induced neurotoxicity in rats. Brain Res 1998;795:257-263.

-45 Yeh SY: N-tert-butyl- $\alpha$-phenylnitrone protects against 3,4-methylenedioxymethamphetamine-induced depletion of serotonin in rats. Synapse 1999;31:169-177.

46 Darvesh AS, Gudelsky GA: The relationship between hyperthermia and glycogenolysis in 3,4-methylenedioxymethamphetamine-induced serotonin depletion in rats. Neurotoxicol Teratol 2004:26:571-577.

-47 Green AR, O'Shea E, Colado MI: A review of the mechanisms involved in the acute MDMA (ecstasy)-induced hyperthermic response. Eur J Pharmacol 2004;500:3-13.

$\checkmark 48$ Colado MI, Green AR: The spin trap reagent $\alpha$-phenyl-N-tert-butyl nitrone prevents 'ecstasy'-induced neurodegeneration of 5-hydroxytryptamine neurones. Eur J Pharmacol 1995;280:343-346.

49 Gudelsky GA: Effect of ascorbate and cysteine on the 3,4-methylenedioxymethamphetamine-induced depletion of brain serotonin. J Neural Transm 1996;103:1397-1404. 
50 Aguirre N, Barrionuevo M, Ramírez MJ, Del Río J, Lasheras B: $\alpha$-Lipoic acid prevents 3,4-methylenedioxymethamphetamine (MDMA)-induced neurotoxicity. Neuroreport 1999;10:3675-3680.

51 Sprague J, Nichols DE: The monoamine oxidase-B inhibitor 1-deprenyl protects against 3,4-methylenedioxymethamphetamine-induced lipid peroxidation and long-term serotonergic deficits. J Pharmacol Exp Ther 1995;273:667-673.

52 Colado MI, O’Shea E, Granados R, Murray TK, Green AR: In vivo evidence for free radical involvement in the degeneration of rat brain 5-HT following administration of MDMA (ecstasy) and p-chloroamphetamine but not the degeneration following fenfluramine. Br J Pharmacol 1997;121:889-900.

53 Darvesh AS, Yamamoto BK, Gudelsky GA: Evidence for the involvement of nitric oxide in 3,4-methylenedioxymethamphetamineinduced serotonin depletion in the rat brain. J Pharmacol Exp Ther 2005;312:694-701.

54 Colado MI, O’Shea E, Esteban B, Granados $\mathrm{R}$, Green AR: In vivo evidence against clomethiazole being neuroprotective against MDMA ('ecstasy')-induced degeneration of rat brain 5-HT nerve terminals by a free radical scavenging mechanism. Neuropharmacology 1999;38:307-314.

55 Colado MI, O’Shea E, Granados R, Esteban B, Martin AB, Green AR: Studies on the role of dopamine in the degeneration of 5-HT nerve endings in the brain of dark agouti rats following 3,4-methylenedioxymethamphetamine (MDMA or 'ecstasy') administration. Br J Pharmacol 1999;126:911-924.

-56 Shankaran M, Yamamoto BK, Gudelsky GA: Mazindol attenuates the 3,4-methylenedioxymethamphetamine-induced formation of hydroxyl radicals and long-term depletion of serotonin in the striatum. J Neurochem 1999;72:2516-2522.

-57 Shankaran M, Yamamoto BK, Gudelsky GA: Involvement of the serotonin transporter in the formation of hydroxyl radicals induced by 3,4-methylenedioxymethamphetamine. Eur J Pharmacol 1999;385:103-110.

-58 Shankaran M, Yamamoto BK, Gudelsky GA: Ascorbic acid prevents 3,4-methylenedioxymethamphetamine (MDMA)-induced hydroxyl radical formation and the behavioral and neurochemical consequences of the depletion of brain 5-HT. Synapse 2001;40:5564.

59 Breier JM, Bankson MG, Yamamoto BK: Ltyrosine contributes to (+/-)-3,4-methylenedioxymethamphetamine-induced serotonin depletions. J Neurosci 2006;26: 290-299.

-60 Goñi-Allo B, Ramos M, Hervias I, Lasheras B, Aguirre N: Studies on striatal neurotoxicity caused by the 3,4-methylenedioxymethamphetamine/malonate combination: implications for serotonin/dopamine interactions. J Psychopharmacol 2006;20:245256.
61 Sprague JE, Everman SL, Nichols DE: An integrated hypothesis for the axonal loss induced by 3,4-methylenedioxymethamphetamine. Neurotoxicology 1998;19:427-442.

62 Miller RT, Lau SS, Monks TJ: 2,5-Bis-(glutathion-S-yl)- $\alpha$-methyldopamine, a putative metabolite of (+/-)-3,4-methylenedioxyamphetamine, decreases brain serotonin concentrations. Eur J Pharmacol 1997;323:173180.

63 Bai F, Lau SS, Monks TJ: Glutathion and Nacetylcysteine conjugates of $\alpha$-methyldopamine produce serotonergic neurotoxicity: possible role in methylenedioxyamphetamine-mediated neurotoxicity. Chem Res Toxicol 1999;20:1150-1157.

64 Bai F, Jones DC, Lau SS, Monks TJ: Serotonergic neurotoxicity of 3,4-(+/-)-methylenedioxyamphetamine and 3,4-(+/-)-methylenedioxymethamphetamine (ecstasy) is potentiated by inhibition of $\gamma$-glutamyl transpeptidase. Chem Res Toxicol 2001;14: 863-870.

65 Esteban E, O'Shea E, Camarero J, Sanchez V, Green RA, Colado MI: 3,4-methylenedioxymethamphetamine induces monoamine release, but not toxicity, when administered centrally at a concentration occurring following a peripherally injected neurotoxic dose. Psychopharmacology 2001;154:251260.

66 Goñi-Allo B, Puerta E, O Mathúna B, Hervias I, Lasheras B, de la Torre R, Aguirre N On the role of tyrosine and peripheral metabolism in 3,4-methylenedioxymethamphetamine-induced serotonin neurotoxicity in rats. Neuropharmacology 2008;54:885900.

67 Schmidt CJ, Wu L, Lovenberg W: Methylenedioxymethamphetamine: a potentially neurotoxic amphetamine analogue. Eur J Pharmacol 1986;124:175-178.

68 Stone DM, Hanson GR, Gibb JW: Differences in the central serotonergic effects of methylenedioxymethamphetamine (MDMA) in mice and rats. Neuropharmacology 1987;26: 1657-1661.

69 Logan BJ, Laverty R, Sanderson WD, Yee YB: Differences between rats and mice in MDMA (methylenedioxymethamphetamine) neurotoxicity. Eur J Pharmacol 1988;152:227234.

70 McKenna DJ, Peroutka SJ: Neurochemistry and neurotoxicity of 3,4-methylenedioxymethamphetamine (MDMA, 'ecstasy'). J Neurochem 1990;54:14-22.

71 Gough B, Ali SF, Slikker W Jr, Holson RR: Acute effects of 3,4-methylenedioxymethamphetamine (MDMA) on monoamines in rat caudate. Pharmacol Biochem Behav 1991; 39:619-623.

72 Colado MI, Green AR: A study of the mechanism of MDMA ('ecstasy')-induced neurotoxicity of 5-HT neurones using chlormethiazole, dizocilpine and other protective compounds. Br J Pharmacol 1994;111:131136.
73 Nash JF, Brodkin J: Microdialysis studies on 3,4-methylenedioxymethamphetamine-induced dopamine release: effect of dopamine uptake inhibitors. J Pharmacol Exp Ther 1991;259:820-825

74 Koch S, Galloway MP: MDMA-induced dopamine release in vivo: role of endogenous serotonin. J Neural Transm 1997;104:135146 .

75 Gudelsky GA, Nash JF: Carrier-mediated release of serotonin by 3,4-methylenedioxymethamphetamine: implications for serotonin-dopamine interactions. J Neurochem 1996;66:243-249.

76 Schmidt CJ, Sullivan CK, Fadayel GM: Blockade of striatal 5-hydroxytryptamine2 receptors reduces the increase in extracellular concentrations of dopamine produced by the amphetamine analogue 3,4-methylenedioxymethamphetamine. J Neurochem 1994;62:1382-1389.

77 Yamamoto BK, Nash JF, Gudelsky GA: Modulation of methylenedioxymethamphetamine-induced striatal dopamine release by the interaction between serotonin and $\gamma$ aminobutyric acid in the substantia nigra. J Pharmacol Exp Ther 1995;273:1063-1070.

78 Nash JF: Ketanserin pretreatment attenuates MDMA-induced dopamine release in the striatum as measured by in vivo microdialysis. Life Sci 1990;47:2401-2408.

79 Schmidt CJ, Black CK, Taylor VL, Fadayel GM, Humphreys TM, Nieduzak TR, Sorensen SM: The 5-HT2 receptor antagonist, MDL 28,133A, disrupts the serotonergic-dopaminergic interaction mediating the neurochemical effects of 3,4-methylenedioxymethamphetamine. Eur J Pharmacol 1992; 220:151-159

80 Schmidt CJ, Fadayel GM, Sullivan CK, Taylor VL: 5-HT2 receptors exert a state-dependent regulation of dopaminergic function: studies with MDL 100,907 and the amphetamine analogue, 3,4-methylenedioxymethamphetamine. Eur J Pharmacol 1992;223: 65-74.

81 Huang X, Nichols DE: 5-HT2 receptor-mediated potentiation of dopamine synthesis and central serotonergic deficits. Eur J Pharmacol 1993;238:291-296.

82 Gudelsky GA, Yamamoto BK, Nash JF: Potentiation of 3,4-methylenedioxymethamphetamine-induced dopamine release and serotonin neurotoxicity by 5 -HT2 receptor agonists. Eur J Pharmacol 1994;264:325330.

83 Kanthasamy A, Sprague JE, Shotwell JR, Nichols DE: Unilateral infusion of a dopamine transporter antisense into the substantia nigra protects against MDMA-induced serotonergic deficits in the ipsilateral striatum. Neuroscience 2002;114:917-924. 
84 Schmidt CJ, Abbate GM, Black CK, Taylor VL: Selective 5-hydroxytryptamine2 receptor antagonists protect against the neurotoxicity of methylenedioxymethamphetamine in rats. J Pharmacol Exp Ther 1990;255:478483.

85 Nash JF, Nichols DE: Microdialysis studies on 3,4-methylenedioxyamphetamine and structurally related analogues. Eur J Pharmacol 1991;200:53-58.

-86 Sprague JE, Huang X, Kanthasamy A, Nichols DE: Attenuation of 3,4-methylenedioxymethamphetamine (MDMA)-induced neurotoxicity with the serotonin precursors tryptophan and 5-hydroxytryptophan. Life Sci 1994;55:1193-1198.

\$87 Boado RJ, Li JY, Nagaya M, Zhang C, Pardridge WM: Selective expression of the large neutral amino acid transporter at the blood-brain barrier. Proc Natl Acad Sci USA 1999;96:12079-12084.

88 Colado MI, Murray TK, Green AR: 5-HT loss in rat brain following 3,4-methylenedioxymethamphetamine (MDMA), p-chloroamphetamine and fenfluramine administration and effects of chlormethiazole and dizocilpine. Br J Pharmacol 1993;108:583589.

89 Bankson MG, Yamamoto BK: SerotoninGABA interactions modulate MDMA-induced mesolimbic dopamine release. J Neurochem 2004;91:852-859.

-90 Nash JF, Meltzer HY, Gudelsky GA: Effect of 3,4-methylenedioxymethamphetamine on 3,4-dihydroxyphenylalanine accumulation in the striatum and nucleus accumbens. J Neurochem 1990;54:1062-1067.

-91 Faraj BA, Olkowski ZL, Jackson RT: Active $[3 \mathrm{H}]$-dopamine uptake by human lymphocytes: correlates with serotonin transporter activity. Pharmacology 1994;48:320-327.

$\checkmark 92$ Hrometz SL, Brown AW, Nichols DE, Sprague JE: 3,4-methylenedioxymethamphetamine (MDMA, ecstasy)-mediated production of hydrogen peroxide in an in vitro model: the role of dopamine, the serotoninreuptake transporter, and monoamine oxidase-B. Neurosci Lett 2004;367:56-59.

$\$ 93$ Jones DC, Lau SS, Monks TJ: Thioether metabolites of 3,4-methylenedioxyamphetamine and 3,4-methylenedioxymethamphetamine inhibit human serotonin transporter (hSERT) function and simultaneously stimulate dopamine uptake into hSERT-expressing SK-N-MC cells. J Pharmacol Exp Ther 2004;311:298-306.

$\$ 94$ Saldana SN, Barker EL: Temperature and 3,4-methylenedioxymethamphetamine alter human serotonin transporter-mediated dopamine uptake. Neurosci Lett 2004;354: 209-212.
95 Sanchez V, Camarero J, Esteban B, Peter MJ, Green AR, Colado MI: The mechanisms involved in the long-lasting neuroprotective effect of fluoxetine against MDMA ('ecstasy')-induced degeneration of 5-HT nerve endings in rat brain. $\mathrm{Br} \mathrm{J}$ Pharmacol 2001;134:46-57.

96 Schmidt CJ: Neurotoxicity of the psychedelic amphetamine, methylenedioxymethamphetamine. J Pharmacol Exp Ther 1987; 240:1-7.

97 Falk EM, Cook VJ, Nichols DE, Sprague JE: An antisense oligonucleotide targeted at $\mathrm{MAO}-\mathrm{B}$ attenuates rat striatal serotonergic neurotoxicity induced by MDMA. Pharmacol Biochem Behav 2002;72:617-622.

98 Stone DM, Johnson M, Hanson GR, Gibb JW: Role of endogenous dopamine in the central serotonergic deficits induced by methylenedioxymethamphetamine.JPharmacol Exp Ther 1988;247:79-87.

99 Schmidt CJ, Black CK, Taylor VL: Antagonism of the neurotoxicity due to a single administration of methylenedioxymethamphetamine. Eur J Pharmacol 1990;181: 59-70.

100 Schmidt CJ, Black CK, Taylor VL: L-DOPA potentiation of the serotonergic deficits due to a single administration of 3,4-methylenedioxymethamphetamine, $\mathrm{p}$-chloroamphetamine or methamphetamine to rats. Eur J Pharmacol 1991;203:41-49.

101 Simantov R, Tauber M: The abused drug MDMA (ecstasy) induces programmed death of human serotonergic cells. FASEB J 1997;11:141-146.

102 Nixdorf WL, Burrows KB, Gudelsky GA, Yamamoto BK: Enhancement of 3,4-methylenedioxymethamphetamine neurotoxicity by the energy inhibitor malonate. J Neurochem 2001;77:647-654.

103 O’Shea E, Orio L, Escobedo I, Sanchez V, CamareroJ, Green AR, Colado MI:MDMAinduced neurotoxicity: long-term effects on 5-HT biosynthesis and the influence of ambient temperature. Br J Pharmacol 2006; 148:778-785

104 Puerta E, Hervias I, Goñi-Allo B, Lasheras B, Jordan J, Aguirre N: Phosphodiesterase 5 inhibitors prevent 3,4-methylenedioxymethamphetamine-induced 5-HT deficits in the rat. J Neurochem 2009;108:755-766.

105 De la Torre R, Farre M: Neurotoxicity of MDMA (ecstasy): the limitations of scaling from animals to humans. Trends Pharmacol Sci 2004; 25:505-508.

106 De la Torre R, Farre M, Roset PN, Pizarro $\mathrm{N}$, Abanades S, Segura M, Segura J, Cami J: Human pharmacology of MDMA: pharmacokinetics, metabolism, and disposition. Ther Drug Monit 2004;26:137-144.

107 Monks TJ, Jones DC, Bai F, Lau SS: The role of metabolism in 3,4-(+)-methylenedioxyamphetamine and 3,4-(+)-methylenedioxymethamphetamine (ecstasy) toxicity. Ther Drug Monit 2004;26:132-136.
108 Hiramatsu M, Kumagai Y, Unger SE, Cho AK: Metabolism of methylenedioxymethamphetamine: formation of dihydroxymethamphetamine and quinone identified as its glutathione adduct. J Pharmacol Exp Ther 1990;254:521-528.

109 Miller RT, Lau SS, Monks TJ: Metabolism of 5-(glutathion-Syl)- $\alpha$-methyldopamine following intracerebroventricular administration to male Sprague-Dawley rats. Chem Res Toxicol 1995;8:634-641.

110 Miller RT, Lau SS, Monks TJ: Effects of intracerebroventricular administration of 5 -(glutathion-S-yl)- $\alpha$-methyldopamine on brain dopamine, serotonin, and norepinephrine concentrations in male SpragueDawley rats. Chem Res Toxicol 1996;9:457465.

111 Easton N, Fry J, O'Shea E, Watkins A, Kingston S, Marsden CA: Synthesis, in vitro formation, and behavioural effects of glutathione regioisomers of $\alpha$-methyldopamine with relevance to MDA and MDMA (ecstasy). Brain Res 2003;987:144-154.

112 Jones DC, Duvauchelle C, Olsen CM, Lau SS, de la Torre R, Monks TJ: Serotonergic neurotoxic metabolites of ecstasy identified in rat brain. J Pharmacol Exp Ther 2005; 313:422-431.

113 Capela JP, Macedo C, Branco PS, Ferreira LM, Lobo AM, Fernandes E, Remião F, Bastos ML, Dirnagl U, Meisel A, Carvalho F: Neurotoxicity mechanisms of thioether ecstasy metabolites. Neuroscience 2007;146: 1743-1757.

114 Carvalho M, Remião F, Milhazes N, Borges F, Fernandes E, Monteiro Mdo C, Gonçalves MJ, Seabra V, Amado F, Carvalho F, Bastos ML: Metabolism is required for the expression of ecstasy-induced cardiotoxicity in vitro. Chem Res Toxicol 2004;17:623632.

115 Carvalho M, Milhazes N, Remiao F, Borges F, Fernandes E, Amado F, Monks TJ, Carvalho F, Bastos ML: Hepatotoxicity of 3,4methylenedioxyamphetamine and $\alpha$-methyldopamine in isolated rat hepatocytes: formation of glutathione conjugates. Arch Toxicol 2004;78:16-24.

-116 Carvalho M, Remião F, Milhazes N, Borges F, Fernandes E, Carvalho F, Bastos ML: The toxicity of $\mathrm{N}$-methyl- $\alpha$-methyldopamine to freshly isolated rat hepatocytes is prevented by ascorbic acid and $\mathrm{N}$-acetylcysteine. Toxicology 2004;200:193-203.

- 117 Carvalho M, Hawksworth G, Milhazes N, Borges F, Monks TJ, Fernandes E, Carvalho F, Bastos ML: Role of metabolites in MDMA (ecstasy)-induced nephrotoxicity: an in vitro study using rat and human renal proximal tubular cells. Arch Toxicol 2002;76: 581-588. 
-118 Capela JP, Meisel A, Abreu AR, Branco PS, Ferreira LM, Lobo AM, Remião F, Bastos ML, Carvalho F: Neurotoxicity of Ecstasy metabolites in rat cortical neurons, and influence of hyperthermia. J Pharmacol Exp Ther 2006;316:53-61.

-119 Capela JP, Ruscher K, Lautenschlager M, Freyer D, Dirnagl U, Gaio AR, Bastos ML, Meisel A, Carvalho F: Ecstasy-induced cell death in cortical neuronal cultures is serotonin-2A-receptor-dependent and potentiated under hyperthermia. Neuroscience 2006;139:1069-1081.

120 Carmo H, Brulport M, Hermes M, Oesch F, Silva R, Ferreira LM, Branco PS, Boer D, Remião F, Carvalho F, Schön MR, Krebsfänger N, Doehmer J, Bastos Mde L, Hengstler JG: Influence of CYP2D6 polymorphism on 3,4-methylenedioxymethamphetamine ('Ecstasy') cytotoxicity. Pharmacogenet Genomics 2006;16:789-799.
121 Easton N, Marsden CA: Ecstasy: are animal data consistent between species and can they translate to humans? J Psychopharmacol 2006;20:194-210.

122 Farfel GM, Seiden LS: Role of hypothermia in the mechanism of protection against serotonergic toxicity. I. Experiments using 3,4-methylenedioxymethamphetamine, dizocilpine, CGS 19755 and NBQX. J Pharmacol Exp Ther 1995;272:860-867.

123 Che S, Johnson M, Hanson GR, Gibb JW: Body temperature effect on methylenedioxymethamphetamine-induced acute decrease in tryptophan hydroxylase activity. Eur J Pharmacol 1995;293:447-453.

124 Malberg JE, Sabol KE, Seiden LS: Co-administration of MDMA with drugs that protect against MDMA neurotoxicity produces different effects on body temperature in the rat. J Pharmacol Exp Ther 1996;278: 258-267.

125 Taraska T, Finnegan KT: Nitric oxide and the neurotoxic effects of methamphetamine and 3,4-methylenedioxymethamphetamine. J Pharmacol Exp Ther 1997; 280:941-947.
126 Colado MI, Granados R, O’Shea E, Esteban B, Green AR: Role of hyperthermia in the protective action of clomethiazole against MDMA ('ecstasy')-induced neurodegeneration, comparison with the novel NMDA channel blocker AR-R15896AR. Br J Pharmacol 1998;124:479-484.

127 Colado MI, Esteban B, O'Shea E, Granados R, Green AR: Studies on the neuroprotective effect of pentobarbitone on MDMA-induced neurodegeneration. Psychopharmacology 1999;142:421-425.

128 O'Shea E, Easton N, Fry JR, Green AR, Marsden CA: Protection against 3,4-methylenedioxymethamphetamine-induced neurodegeneration produced by glutathione depletion in rats is mediated by attenuation of hyperthermia. J Neurochem 2002; 81:686-695.

129 Morley KC, Li KM, Hunt GE, Mallet PE, McGregor IS: Cannabinoids prevent the acute hyperthermia and partially protect against the 5-HT depleting effects of MDMA ('Ecstasy') in rats. Neuropharmacology 2004;46:954-965. 